for a convenient length to divide into a thousand parts, did not take up the already existing yard, which is nearly the same as the metre. Yard $\div 1000=($ metre $\div$ I000 $)-.004$ inch. The amount of confusion that would have been saved is almost incalculable.

The metric system usually carries with it the Centigrade scale on the thermometer, and here the whole English-speaking world should give no uncertain sound. I am not contending for any scale in chemistry or geology, but in meteorology it would be difficult to find a worse scale than the Centigrade. The plea that we must have just $100^{\circ}$ between the freezing and boiling points does not hold ; any convenient number of degrees would do. The Centigrade degree $\left(\mathrm{I}^{\circ} \cdot 8 \mathrm{~F}\right.$. $)$ is just twice too large for ordinary studies. The worst difficulty, however, is in the use of the Centigrade scale below freezing. Any one who has had to study figures, half of which have minus signs before them, knows the amount of labour involved. To average a column of thirty figures, half of which are minus, takes nearly double time that figures all on one side would take, and the liability to error is more than twice as great. I have found scores of errors in foreign publications where the Centigrade scale was employed, all due to this most inconvenient minus sign. If any one ever gets a "bee in his bonnet" on this subject, and desires to make the change on general principles, it is very much to be hoped that he will write down a column of thirty figures half below $32^{\circ} \mathrm{F}$., then convert them to the Centigrade scale, and try to average them. I am sure no English meteorologist who has ever used the Centigrade scale, will ever desire to touch it. It is much easier and safer to convert the Centigrade scale to the Fahrenheit before any studies are made. As a matter of fact, Euro. pean temperatures are a sealed book to active workers in meteorology on account of this unfortunate scale.

England and the United States may congratulate themselves, however, in the fact that European meteorology is almost flat. There are no low area or high area systems moving with regularity at any definite speed or in any definite direction, such as are experienced in the United States three or four times in a month. The rains in Europe are mostly sporadic, and do not accompany any well-defined low areas.

If any change is to be made, cannot the meteorological world come together upon a thermometer having its zero at $-40^{\circ}$ both Fahrenheit and Centigrade. This would be a most convenient scale, and would eliminate nearly all minus signs. The conversions from the old to the new would be very convenient by simply adding $40^{\circ}$ to each. The conversion from the new Fahrenheit to the new Centigrade would also be extremely convenient by dividing by $\mathrm{I} \cdot 8$ instead of the present very puzzling system, and vice versa, Centigrade degrees $+\mathrm{I} \cdot 8$ would give the Fahrenheit value. This would obviate the difficulty of the minus sign, but there would still remain the fact that the Fahrenheit degree is by far better than the Centigrade.

Washington, D.C., December 18, I895. H. A. Hazen.

\section{Apparatus for determining the Specific Gravity of} Minute Fragments of Minerals.

THIs is a contrivance designed to facilitate the measurement of the specific gravities of minute fragments of minerals by means of a diffusion column of methylene iodide, as described by Prof. Sollas in Nature, vol. xliii. p. 404, and vol, xlix. p. 2II. There is no new principle involved in the construction of the instrument. It is merely the adaptation to this particular purpose of a well-known device for getting rid of the error due to parallax, such as is employed in Prof. Joly's spring balance for determining specific gravities, and the best form of tangent galvanometer. The index, which in this case is a fine wire, or fibre of any kind, is reflected in a mirror placed behind it, the coincidence of the fibre and its reflection showing that the eye of the observer is exactly on a level with the index.

In the drawing, $a$ (Fig. I) is a test tube containing the methylene iodide column in which the fragments of mineral under observation are immersed, together with two or more beads or fragments of mineral whose specific gravity is known. This is held by a clip, $b$, in a slot cut through the upper end of a thin piece of wood, some $\mathrm{r} 2$ inches high, fixed vertically to a firm base, so as to bring the test tube and its contents to a convenient height above the table. A slip of mirror, $d$, carrying a scale, $e$, divided in millimetres or any even graduations, is fixed vertically at the side of the slot, and the fibre is carried by a slider, $c$, which is shown separately in Fig. 2. This may be made of a strip of thin sheet copper, and has a "window" cut through it at $b$, so that the contents of the test tube may be seen.

The readings are taken by bringing the fibre successively on a level with the approximate centre of gravity of each fragment,

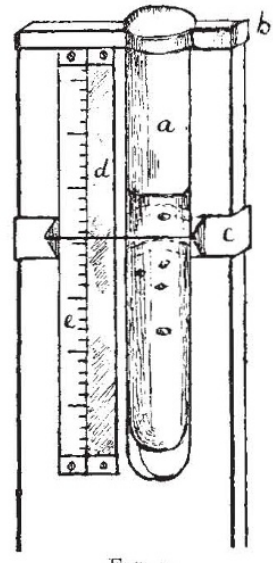

Fig. I.

ancl noting the division of the scale cut by it, taking care that it coincides with its reflection in the mirror at each reading. The instrument might be improved by making the scale movable through a short distance vertically, so that one of the larger divisions of the scale might always be brought on a level with

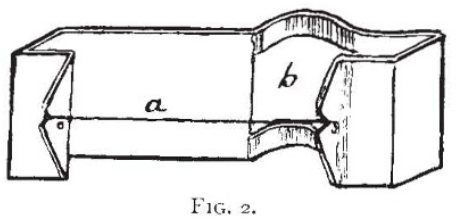

the uppermost of the beads or fragments used as indicators. The whole thing may be made at a cost of less than a shiliing. It has been tried in the geological laboratory of the Royal College of Science for Ireland with satisfactory results.

\section{T. D. LA TOUChe.}

\section{Cactace $æ$ in the Galapagos Islands.}

Mr. Heusley is mistaken in stating, as he does on p. 623 of NATURE for October 24, I895, that Dr. G. Baur was attached to the U.S. Fish Commission Steamer Albatross. Dr. Baur had no connection with the Albatross Expedition of I891, the object of which was deep-sea dredging, and only included an incidental visit of a few days to the Galapagos. Nor did Dr. Baur write the general sketch of that expedition, or have anything to do with the photographs which accompany it, as one might infer from a subsequent note by Mr. Hemsley on the Cactacex of the Galapagos (Nature, November I4, I895, p. 31).

As regards the Cactacere of those islands, I collected branches of Opuntia and of Cereus from Chatham and from Charles Islands ; what became of those pieces I do not know, as they do not seem to have reached the hands of Dr. J. N. Rose, who described the plants collected at the Galapagos by the Albatross Expedition.

Mr. Hemsley will find that both Dr. Wolf and myself state that Cereus grows to 20 feet in height. Dr. Wolf also called attention to some striking differences he had noticed in the specimens of Opuntia and of Cereus he found on the different islands.

In stating his position, botanically speaking, regarding Dr. Baur's theory of the origin of the Galapagos, Mr. Hemsley would surely not give us to understand that Opuntia and Cerezes are limited to Chili on the west coast of South America, as his second note (p. 3i) seems to imply. Alexander Agassiz.

Museum of Comparative Zoology, Cambridge, Mass., December 2, I895.

[Mr. Hemsley admitted, in NATURE of November 28, I895, that he was in error in thinking Dr. Baur was attached to the U.S. Fish Commission Steamer Albatross.-ED. NATURE.]

NO. I 366 , VOL. 53] 